\title{
Reduce the Loss Iron
}

\section{in the Wet Separation in High Fields}

\author{
Edward K. Yakubailik*a, Igor M. Ganzhenkob, \\ Pavel Yu. Butov and Vladimir I. Kilin ${ }^{\mathrm{c}}$ \\ ${ }^{a} L . V$. Kirensky Institute of Physics, SB RAS \\ 50/38 Akademgorodok, Krasnoyarsk, 660036, Russia \\ ${ }^{b} J S C$ Evrazruda \\ 39 Kondomskoe Highway, Novokuznetsk, 654018, Russia \\ 'JSC MMC «Kazakhaltyn» \\ 5 Bld., 6 Mkr., Stepnogorsk, 021500, Kazakhstan
}

Received 10.06.2016, received in revised form 11.08.2016, accepted 12.11.2016

Contains the results of research to reduce the loss of magnetite iron in the wet processing of iron concentrates in high magnetic fields.

Magnetite iron losses due to the low value of the magnetic characteristics of thin-less 50 micron grade magnetite. To increase the magnetic force of attraction is necessary to raise the intensity of the magnetic field and its gradient separation. Wet magnetic analysis showed that the loss of iron in magnetite fields $H=480 \mathrm{kA} / \mathrm{m}$ half as much as in the field $H=80 \mathrm{kA} / \mathrm{m}$; loss in the conditions of high-gradient separation to about $0.1 \%$.

Loss of magnetite iron tailings Abagurskom concentrator averaged made in $2013-0.9 \%$ in $2014-0.89 \%$. The factory upgraded separator 28 PBM90/250 to the replacement of magnetic systems ferrite barium neodymium-iron-boron; wherein the field strength is increased from 111 to $175 \mathrm{kA} / \mathrm{m}$.

Keywords: final tailings, loss, iron magnetite, barium ferrite, neodymium-iron-boron magnetic parameters.

Citation: Yakubailik E.K., Ganzhenko I.M., Butov P.Yu., Kilin V.I. Reduce the loss iron in the wet separation in high fields, J. Sib. Fed. Univ. Eng. technol., 2016, 9(8), 1302-1310. DOI: 10.17516/1999-494X-2016-9-8-1302-1310.

(c) Siberian Federal University. All rights reserved

* Corresponding author E-mail address: yakubailik@gmail.com 


\title{
Снижение потерь железа
}

\section{при мокрой сепарации в высоких полях}

\author{
Э.К. Якубайлика \\ П.Ю. Бутов ${ }^{\sigma}$, В.И. Килин \\ ${ }^{a}$ Институт физики им. Л.В. Киренского СО РАН \\ Россия, 660036, Красноярск, Академгородок 50/38 \\ ${ }^{6} \mathrm{OAO}$ «ввразруда» \\ Россия, 654018, Новокузнецк, Кондомское шоссе, 39 \\ 'ЗАО ГМК «Казахалтын», \\ Казахстан, 021500, Степногорск, мкр. 6, стр. 5
}

Изложены результаты исследований по снижению потерь магнетитового железа при мокром обогащении железорудных концентратов в высоких магнитных полях.

Потери магнетитового железа обусловлены низкими величинами магнитных характеристик тонких -менее 50 микрон - классов магнетита. Для увеличения магнитной силь притяжения необходимо поднимать напряженность магнитного поля сепарации и его градиент. Мокрый магнитный анализ показал, что потери магнетитового железа в полях $H=480$ ка/м вдвое меньше, чем в поле $H=80 \mathrm{\kappa a} / \mathrm{m} ;$ потери же в условиях высокоградиентной сепарации до $\sim 0,1 \%$.

Потери магнетита с отвальными хвостами Абагурской обогатительной фабрики усредненно составили в 2013 г. 0,9 \%, в 2014 г. - 0,89 \%. На фабрике модернизировано 28 сепараторов ПБМ90/250 с заменой в магнитных системах феррита бария на неодим-железо-бор; при этом напряженность поля возросла со 111 до $175 \mathrm{\kappa a} / \mathrm{M}$.

Ключевые слова: отвальные хвосты, потери, железо магнетитовое, феррит бария, неодимжелезо-бор, магнитные параметры.

\section{Введение}

Одним из основных показателей эффективности обогащения железорудного сырья на фабрике магнитного обогащения является величина потерь магнетитового железа с хвостами.

Абагурская обогатительная фабрика ОАО «Евразруда» производит для металлургов вторичный железорудный концентрат, обогащая промпродукты (первичные концентраты) многих сибирских месторождений.

Присутствие в рудной шихте наряду с магнетитом его псевдоморфоз по гематиту и примесей последнего, железосиликатов, сульфидов железа разного состава приводит к значительным колебаниям магнитных характеристик самого магнетита и в итоге - к дополнительным потерям железа с хвостами обогащения.

В статье собраны данные по потерям железа на рудничных дробильно-обогатительных «сухих» фабриках и на заключительной стадии получения железорудного концентрата - мокрой магнитной сепарации - на Абагурской обогатительной фабрике. Рассмотрены способы снижения потерь при магнитной сепарации и возможности их практической реализации на фабриках.

Публикация содержит результаты совместных исследований сотрудников Института физики СО РАН и специалистов Абагурского филиала ОАО «Евразруда». 


\section{«Текущие» потери железа \\ на сибирских обогатительных фабриках}

В литературе достаточно информации по проблемам переработки техногенного сырья [1]. Актуальность обсуждаемой тематики подтверждают цифры. Приведем их. Только на горнообогатительных предприятиях «основного» сибирского «обогатителя» железных руд - ОАО «Евразруда» - ежегодно вырабатывается свыше 5 млн т хвостов. На сегодня в отвалах и шламохранилищах накоплено свыше 240 млн т отходов обогащения железных руд. В том числе на Абагурской обогатительной фабрике в трех хранилищах содержится свыше 90 млн т шламов, на Мундыбашской фабрике - более 45 млн т. Отсюда ясно, что должны проводиться направленные исследования по снижению потерь извлекаемого железа в этих отходах и изучение способов их утилизации по мере роста наших технических возможностей.

Сырье Абагурской фабрики - первичные концентраты сухой магнитной сепарации рудников Горной Шории, Хакасии, Красноярского края. В табл. 1 содержатся данные о качестве этих концентратов и потерях железа в хвостах магнитного анализа материала из них при крупности -0,07+0 мм и напряженности извлекающего поля $\mathrm{H}=80$ кА/м, а также основная магнитная характеристика полученных концентратов. Химический анализ проб выполнен в Центральной технологической лаборатории ОАО «Евразруда».

Выход хвостов от $\sim 56$ до $32 \%$; содержание железа общего от 20,6 до 8,3 \%, магнетитового - от $\sim 3,8$ до $1,5 \%$. Приведенные величины потерь - это уровень потерь, с которыми промпродукты поступают на Абагур, так называемые заложенные потери.

Как видно из табл. 1, повышенное содержание потерь магнетита коррелирует с содержанием серы в исходном промпродукте и с пониженной удельной намагниченностью насыщения (см. пробы Изых-Гола).

Таблица 1. Потери железа с хвостами при ММА первичных концентратов

\begin{tabular}{|l|c|c|c|c|c|c|c|}
\hline \multicolumn{3}{|c|}{ Первичные концентраты } & \multicolumn{5}{c|}{ Мокрый магнитный анализ } \\
\hline \multirow{2}{*}{ Проба } & \multicolumn{2}{|c|}{ Содержание, \% } & \multicolumn{3}{c|}{ Отходы } & \multicolumn{2}{c|}{ Концентрат } \\
\cline { 2 - 9 } & Fе общ. & $\mathrm{S}$ & Выход, \% & $\begin{array}{c}\text { Fe общ., } \\
\%\end{array}$ & $\begin{array}{c}\text { Fe маг., } \\
\%\end{array}$ & Fe общ., \% & $\begin{array}{c}\sigma_{\mathrm{s},} \\
\mathrm{A}^{*} \text { м }^{2} \text { кг }\end{array}$ \\
\hline Тея & 36,5 & 0,7 & 48,5 & 9,0 & 1,87 & 61,3 & 73,7 \\
\hline Изых-Гол & 41,2 & 2,8 & 56,5 & 20,6 & 3,83 & 67,3 & 57,7 \\
\hline Ирба 42 & 44,9 & 1,4 & 39,5 & 11,3 & 1,91 & 66,4 & 76,7 \\
\hline Ирба 45 & 45,0 & 1,4 & 39,1 & 11,3 & 2,08 & 66,4 & 73,2 \\
\hline Краснокаменск & 38,9 & 0,7 & 54,8 & 14,7 & 1,59 & 65,9 & 71,4 \\
\hline Каз & 47,1 & 3,0 & 35,3 & 15,1 & 1,89 & 64,7 & 75,5 \\
\hline Шерегеш & 41,2 & 1,2 & 40,0 & 8,3 & 1,51 & 63,1 & 78,2 \\
\hline Таштагол & 41,4 & 0,8 & 44,5 & 10,6 & 1,60 & 66,1 & 78,6 \\
\hline Абакан & 50,9 & 2,8 & 31,5 & 17,6 & 2,67 & 66,8 & 82,0 \\
\hline
\end{tabular}

Fe общ. и Fе маг. - железо общее и железо магнетитовое. 


\section{«Природа» потерь магнетита с хвостами}

Потери магнетита с хвостами при магнитном обогащении неизбежны и предопределены физикой ферромагнетизма. По мере измельчения магнетит «раскрывается» с увеличением содержания железа, но при крупности порядка 60 микрон и ниже его магнитные характеристики, определяющие удельную магнитную силу притяжения, заметно снижаются, таким образом, сила, извлекающая его в концентрат, пропорционально падает. В итоге магнитная система сепараторов со «средним» полем $\mathrm{H} \sim$ 1,2 -1,5 кэ не удерживает «тонкие» частицы магнетита, которые и удаляются в хвосты, поднимая в них содержание железа.

Подобную закономерность на магнетитовых рудах ранее наблюдали А.А. Бикбов и Л.В. Крюковская [2], она описана в монографии Л.А. Ломовцева, Н.А. Нестеровой и Л.А. Дробченко [3].

Ситовый анализ отвальных хвостов ДОФ Абаканского рудника свидетельствует о том, что оставшееся в хвостах магнетитовое железо связано преимущественно с тонкими классами. В табл. 2 приведена ситовая характеристика абаканских хвостов крупностью 8-0 мм.

Видно, что в классе - $0,07+0$ мм, составляющем лишь 7 \% отходов, сосредоточен 61 \% потерь магнетитового железа в них. Такие высокие потери в этом классе обусловлены наряду с адгезией при влажной поверхности частиц также и низкими величинами магнитных параметров столь мелких частиц магнетита, уменьшающими их способность к извлечению в концентрат [4].

Увеличение потерь железа при магнитной сепарации железосодержащего сырья заметно на рудах с низкими величинами магнитных параметров. Величины основных магнитных параметров первичных концентратов даны в табл. 3.

Сравним (по табл. 2,3$)$ значения магнитных характеристик $\left(\sigma_{\mathrm{S}}, \chi, \mathrm{H}_{\mathrm{C}}\right)$ промпродуктов магнетитовых руд Шерегеша и Таштагола с аналогами на слабомагнитных рудах Изых-Гола и Теи, а затем сопоставим потери магнетита в хвостах названных проб - они явно больше для слабомагнитных руд.

Коэрцитивная сила $\mathrm{H}_{\mathrm{C}}$ слабомагнитных руд, как правило, выше, чем магнетитовых: Абакана $-4,53$, Шерегеша $-3,47$, Изых-Гола $-10,56$ и Теи - 4,96 кА/м. Все цифры даны для класса крупности $-0,07+0$ мм [5].

Таблица 2. Ситовая характеристика абаканских отвальных сухих хвостов

\begin{tabular}{|c|c|c|c|}
\hline \multirow{2}{*}{ Класс, мм } & \multirow{2}{*}{ Выход, \% } & \multicolumn{2}{|c|}{ Содержание, \% } \\
\cline { 3 - 4 } & & Fе общее & Fе магнетитовое \\
\hline$-8+5,0$ & 21,70 & 10,1 & 1,21 \\
\hline$-5+2,5$ & 29,31 & 10,4 & 1,75 \\
\hline$-2,5+1,25$ & 13,2 & 11,4 & 2,40 \\
\hline$-1,25+0,63$ & 14,54 & 12,0 & 2,89 \\
\hline$-0,63+0,16$ & 7,16 & 11,7 & 1,72 \\
\hline$-0,16+0,071$ & 6,94 & 18,1 & 7,85 \\
\hline$-0,071+0$ & 7,15 & 36,9 & 29,96 \\
\hline ИТОГО & 100,00 & 13,22 & 4,32 \\
\hline
\end{tabular}


Таблица 3. Магнитные характеристики первичных концентратов

\begin{tabular}{|c|c|c|c|c|}
\hline $\begin{array}{l}\text { Первичный } \\
\text { концентрат }\end{array}$ & $\begin{array}{l}\text { Содержание } \\
\text { железа общ. }\end{array}$ & $\begin{array}{c}\text { Удельная } \\
\text { намагниченность } \\
\text { насыщения, } \sigma_{\mathrm{s}}\end{array}$ & $\begin{array}{c}\text { Удельная } \\
\text { магнитная } \\
\text { восприимчивость, } \chi \\
\text { Н=111 кА/м }\end{array}$ & $\begin{array}{c}\text { Коэрцитивная } \\
\text { сила, } \mathrm{H}_{\mathrm{C}}\end{array}$ \\
\hline & $\%$ & $\mathrm{~A}^{*} \mathrm{M}^{2} /$ кг & $10^{-4} \mathrm{M}^{3} / \kappa \Gamma$ & кA / м \\
\hline Тёя & 36,5 & 39,76 & 0,83 & 4,96 \\
\hline Изых-Гол & 41,2 & 26,57 & 0,7 & 10,56 \\
\hline Ирба-42 & 44,9 & 48,00 & 1,13 & 4,09 \\
\hline Ирба-45 & 45,0 & 47,07 & 1,23 & 4,68 \\
\hline Краснокаменск & 38,9 & 33,81 & 0,92 & 6,02 \\
\hline Каз & 47,1 & 48,91 & 1,07 & 4,26 \\
\hline Шерегеш & 41,2 & 48,73 & 1,28 & 3,47 \\
\hline Таштагол & 41,4 & 45,28 & 0,97 & 3,15 \\
\hline Абакан & 50,9 & 56,93 & 1,42 & 4,53 \\
\hline
\end{tabular}

Отметим, что анализ величин полей насыщения $\mathrm{H}_{\mathrm{S}}$ - по данным магнитных измерений - показывает, что $\mathrm{H}_{\mathrm{S}}$ слабомагнитных руд существенно выше полей насыщения магнетитовых руд. Это также приводит к дополнительным потерям железа при магнитной сепарации [6].

\section{Потери магнетита при обогащении в высоких полях}

При магнитном обогащении используют несколько способов снижения потерь железа с хвостами:

- повышение напряженности и градиента магнитного поля сепарации;

- увеличение частоты смены полюсов и угла охвата магнитной системы;

- магнитная подготовка перед сепарацией - магнитные флокуляция и дефлокуляция материала.

Наиболее применяемый - сепарация в полях повышенной напряженности.

Из анализа формулы расчета магнитной силы притяжения

$$
\mathrm{f}_{\mathrm{M}}=\mu_{0} \chi \mathrm{HgradH}
$$

следует, что при обогащении руд с низкими магнитными свойствами, т.е. мала $\chi$, необходимо увеличивать величину HgradH - удельную магнитную силу магнитной системы. Вариантов два: 1) «электромагнит» с большой силой тока; 2) замена материала постоянных магнитов магнитной системы.

Как пример приведем результаты мокрого магнитного анализа четырех проб руд Абагасского железорудного месторождения (Республика Хакасия). Три из них $(61,1,115)$ можно отнести к гематит-магнетитовому составу. Кроме того, в пробе 1 присутствует редкий железо-кальциевый силикат - ильваит, содержащий 41 \% слабомагнитного железа. Проба 73 магнетит-мушкетовитая, обогащенная сульфидами - пиритом.

$$
-1306-
$$


Таблица 4. Потери железа при мокрой сепарации абагасских руд

\begin{tabular}{|c|c|c|c|c|}
\hline \multirow{2}{*}{ Проба } & \multirow{2}{*}{$\mathrm{H}$, кA/м } & \multirow{2}{*}{$\gamma$ н/м, \% } & \multicolumn{2}{|c|}{ Содержание н/м, \% } \\
\cline { 4 - 5 } & & & Fе общ & Fе магн \\
\hline \multirow{2}{*}{73} & 80 & 34,4 & 26,4 & 2,2 \\
\cline { 2 - 5 } & 480 & 34,9 & 25,3 & 1,3 \\
\hline \multirow{2}{*}{61} & 80 & 71,6 & 29,5 & 1,4 \\
\cline { 2 - 5 } & 480 & 69,8 & 28,1 & 0,7 \\
\hline \multirow{2}{*}{1} & 80 & 75,5 & 19,3 & 1,0 \\
\cline { 2 - 5 } & 480 & 75,2 & 18,8 & 0,4 \\
\hline \multirow{2}{*}{115} & 80 & 66,9 & 14,0 & 1,3 \\
\cline { 2 - 5 } & 480 & 67,1 & 13,6 & 0,6 \\
\hline
\end{tabular}

Опыты выполнены на материале 100 \% класса -0,07+0мм в двух полях: Н=80 кА/м, близком к рабочему полю сепаратора ПБМ, и, учитывая, что три пробы содержат слабомагнитные минералы, в высоком поле $\mathrm{H}=480$ кА/м.

В табл. 4 представлены величины потерь железа при сепарации на магнитном анализаторе в названных полях. С ростом поля в концентрат частично извлекаются слабомагнитные минералы и очень бедные сростки, что ведет к уменьшению потерь железа в немагнитном продукте

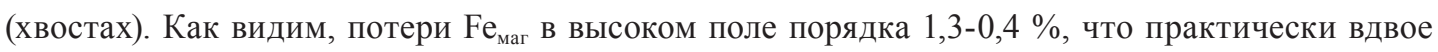
меньше, чем в поле $\mathrm{H}=80$ кА/м для каждой из проб [6].

Крайне малы - десятые доли процента - потери магнетитового железа при сепарации слабомагнитных руд методом ВГМС. Сегодня большие объемы слабомагнитных руд за рубежом и в России, как правило, обогащаются роторными высокоградиентными магнитными сепараторами. Принципы разделения, конструкции сепараторов, практика их применения полно описаны в монографии В.В. и В.И. Кармазиных [7].

Авторами настоящей публикации моделированы условия ВГМС на электромагните ФЛ, между полюсными наконечниками которого помещалась медная кассета, заполненная феррозаполнителем - стальными шарами $\mathrm{d}=5$ мм. Напряженность «первичного» магнитного поля в зазоре электромагнита составляла Н=960 кА/м, на феррозаполнителе же величина неоднородного магнитного поля значительно выше.

Методом ВГМС обогащались пробы № 60, 62 окисленных гематитовых руд Абагасса. В хвостах ВГМ-сепарации содержание железа общего: в пробе № 60 - 14,4 \%, пробе № 62 $32,1 \%$; железа магнетитового в обеих пробах - 0,1 \%. Таким образом, потери железа магнетитового составляют $0,1 \%$; опыты характеризуют изменение потерь магнетитового железа в высоких магнитных полях [8].

\section{Совершенствование магнитных систем с постоянными магнитами}

C 70-80-х гг. ХХ в. за рубежом и в России феррит бария, десятилетиями используемый при создании магнитных систем сепараторов, вытесняется керамикой на основе редкоземельных металлов - самарий-кобальта, неодим-железо-бора и другими с более высокими магнитными параметрами: остаточной индукцией $\mathrm{B}_{\mathrm{r}}$, коэрцитивной силой $\mathrm{H}_{\mathrm{C}}$, магнитной энергией $\mathrm{BH}[9]$.

$$
-1307-
$$


Результат: напряженность поля на поверхности барабана магнитной системы из ферритобариевых блоков составляет $\sim 0,11$ Тл, остаточная индукция $\mathrm{B}_{\text {r }}$ редкоземельных сплавов неодимжелезо-бор достигает 1,2 Тл.

Опыты по измерению магнитных полей и удельной магнитной силы над магнитами показали, что удельная магнитная сила $\mathrm{f}_{\text {м }}$ одной пластины из сплава неодим-железо-бор размером $60 x 80 x 20$ мм более чем в 2,5 раза превышает удельную магнитную силу заводского блока из феррита бария размером 80x135x120 мм, собранного из 12 пластин. В результате напряженность поля сепаратора возрастает со 111 до 175 кА/м на поверхности барабана, градиент поля увеличивается в 1,5 раза; соответственно повышается и извлекающая магнитная сила. Детально измерения (аппаратура, методики) описаны в статье [10].

В развитие этой идеологии на сухих рудничных обогатительных фабриках ОАО «Евразруда» реконструировано около 60 сепараторов: ферритобариевые и электромагнитные системы заменены на магнитные системы из композита неодим-железо-бор. Такая реконструкция позволила увеличить эффект быстроходности (частоту смены полюсов и центробежную силу) обычных промышленных сепараторов и в пересчёте на потери магнетита снизить их в хвостах по всем рудникам «Евразруды» на 0,5-0,6 \%.

Материалы и анализ исследований и промышленных испытаний, выполненных при модернизации магнитных систем сепараторов на дробильно-обогатительных фабриках ОАО «Евразруда», содержатся в монографии В.И. Килина «Повышение эффективности магнитной сепарации магнетитовых руд», изданной в 2011 г. [11].

На Абагурской центральной магнитообогатительной фабрике ОАО «Евразруда» применяется двухстадиальная схема мокрого магнитного обогащения на двух участках с одинаковой технологией и примерно равной производительностью. Концентрат обоих участков собирается для сгущения и фильтрации в одном месте. Новые магнитные системы из композита неодимжелезо-бор установлены на 28 сепараторах ПБМ 90/250 первой и второй стадий и операции сгущения концентрата.

Центральной лабораторией фабрики на двух операциях технологической схемы (второй стадии обогащения и сгущения) проведены сравнительные испытания сепараторов ПБМ90/250 с различными магнитными системами: новыми, из композита неодим-железобор с полем напряжённостью $\mathrm{H}=175$ кА/м, шагом полюсов 90 мм и сепараторов с прежними системами из феррита бария с напряжённостью поля $\mathrm{H}=111$ кА/м, шагом полюсов 140 мм при одинаковой частоте вращения 25 об/мин.

Получены следующие показатели: на второй стадии обогащения, на сепараторе с новыми магнитными системами, содержание железа в концентрате выше на $0,23 \%$, в хвостах содержание магнетитового железа меньше на $0,40 \%$; на операции сгущения, на сепараторе с новыми магнитными системами, содержание железа в концентрате больше на $0,51 \%$, а в хвостах магнетитовое железо ниже на 0,49 \%. Промышленные опыты подтвердили эффективность применения новых магнитных материалов в магнитных системах сепараторов.

За счет этой реконструкции годовые потери в хвостах Абагурской фабрики снижены с $1,20 \%$ в 2010 г. до $0,89 \%$ в 2014 г.

Исследования по изучению потерь в отходах, проведённые на Абагурской фабрике в 2013 г. [12], показали, что потери магнетитового железа могут быть в дальнейшем уменьшены до 0,5- 
0,6 \% против 0,89 \% на сегодня при использовании на всех сепараторах магнитных систем из композита неодим-железо-бор. Из них 0,20 \% снижения потерь будет достигнуто применением на всех операциях сепараторов с полем 175 кА/м и системами неодим-железо-бор и $0,23 \%$ - за счёт установки на операции сгущения перед фильтрацией сепараторов для регенерации суспензий (ПБР) с полем 190 кА/м и системами неодим-железо-бор.

\section{Заключение}

В статье приведены итоги исследований по снижению потерь магнетитового железа при мокрой магнитной сепарации в высоких магнитных полях.

Экспериментально показано, что причины потерь магнетита с хвостами, как правило, следующие:

- низкая центробежная сила;

- связь остающегося в хвостах железа, в основном, с тонкими классами магнетита, менее 70 микрон; падение при такой крупности величин магнитных характеристик ферримагнитных минералов, определяющих силу притяжения;

- низкая частота перемешивания на всех сепараторах, кроме быстроходных;

- резкое возрастание адгезии породных частиц на частицах магнетита.

Для более полного извлечения тонких классов необходимо увеличивать удельную магнитную силу магнитной системы сепараторов, поднимая поле и его градиент, а также центробежную силу, частоту чередования полюсов.

Лабораторная сепарация подтверждает, что в высоких магнитных полях $\mathrm{H}=480$ кА/м потери магнетитового железа с хвостами уменьшаются практически вдвое в сравнении с потерями в поле $\mathrm{H}=80$ кА/м. Об этом же говорят величины потерь магнетитового железа при высокоградиентной магнитной сепарации (ВГМС) слабомагнитных продуктов - в опытах они составили всего $0,1 \%$.

На Абагурской обогатительной фабрике сегодня потери магнетитового железа в пределах $0,9-1 \%$, что является одним из итогов реконструкции магнитных систем сепараторов - замены феррита бария на редкоземельную керамику.

Анализ потерь магнетитового железа на Абагурской фабрике позволяет предположить возможность их снижения до уровня 0,5-0,6 \%. Необходимые условия: применение на всех сепараторах магнитных систем с полем $\mathrm{H}=175$ кА/м, на операции сгущения - установка сепараторов с полем $\mathrm{H}=190$ кА/м для регенерации суспензии. Прирост поля достигается использованием в магнитных системах композитов из неодим-железо-бора.

\section{Список литературы}

[1] Филиппов П.А. О потенциале техногенных образований рудников Западной Сибири. Физико-технические проблемы разработки полезных ископаемых., 2008, 4,71-77. [Filippov P.A. The potential of technogenic formations in mines of the West Siberia, Journal of Mining Science, 2008, vol. 44, no. 4, pp. 386-390 ( in Russian, in English)].

[2] Бикбов А.А.,Крюковская Л.В. Магнитные свойства некоторых магнетитовых промпродуктов. Обогащение руд, 1974, 5,17-20. [Bikbov A.A. and Kryukovskaya L.V. Magnetik Properties of Intermediate Magnetite Products., Obogashchenie Rud, 1974, 5, 17-20.(in Russian)]. 
[3] Ломовцев Л.А., Нестерова Н.А., Дробченко Л.А. Магнитное обогащение сильномагнитных руд. Москва: «Недра», 1979, 235 с.[ Lomovtsev L.A., Nesterova N.A. and Drobchenko L.A. Magnetic Beneficiation of Strongly Magnetic Ores. Moskow, Nedra, 1979, 235.(in Russian)].

[4] Килин В.И., Якубайлик Э.К. Изучение магнитных свойств и процессов сепарации абаканских магнетитов. Физико-технические проблемы разработки полезных ископаемых, 2002, 5, 104-109. [ Kilin V.I., Yakubailik E.K. Investigation into Magnetic Properties and Processes of Separation of Abakan Magnetites, Journal of Mining Science, 2002, vol.38, 5, 506-511.(in Russian, in English)].

[5] Якубайлик Э.К., Килин В.И., Чижик М.В., Ганженко И.М., Килин С.В. Магнитные характеристики первичных концентратов руд - сырья Абагурской фабрики. Физико-технические проблемы разработки полезных ископаемых, 2013, 1, 170-176. [Yakubailik E.K., Kilin V.I., Chizhik M.V., Ganzhenko I.M. and Kilin S.V. Magnetic Characteristics of Primary Concentrates Supplied as a Feedstock to Abagur Enrichment-Agglomeration Plant, Journal of Mining Science, 2013, vol.49, 1, 153-159. (in Russian, in English)].

[6] Килин В.И., Якубайлик Э.К., Костененко Л.П., Ганженко И.М. Изучение обогатимости гематит-магнетитовых руд Абагасского месторождения. Физико-технические проблемы разработки полезных ископаемых, 2012, 2, 160-166.[Kilin V.I., Yakubailik E.K., Kostenenko L.P. and Ganzhenko I.M. Dressability of Abagas Hematite-Magnetite Ores, Journal of Mining Science, 2012, vol.48, 2, 363-368.(in Russian, in English)].

[7] Кармазин В.В., Кармазин В.И. Магнитные, электрические и специальные методы обогащения полезных ископаемых, Т. 1. Высшее горное образование, Москва, Издательство МГГУ, 2005, 670 c.[Karmazin V.M. and Karmazin V.I. Magnetic, Electrical and Special Methods of Mineral Enrichment., vol.1, Moskow, Izd. MSGU, 2005, 670 p. (in Russian)].

[8] Килин В.И., Якубайлик Э.К., Ганженко И.М., Килин С.В. Оценка обогатимости абагазских окисленных руд. Известия вузов. Черная металлургия, 2011, 12, 6-8.[Kilin V.I., Yakubailik E.K., Ganzhenko I.M., Kilin S.V. Estimation dressability of Abagas oxidize ores. Izvestiya vuzov. Ferrous Metallurgiya, 2011, 12, 6-8.(in Russian)].

[9] Пелевин А.Е., Цыпин Е.Ф., Колтунов А.В., Комлев С.Г. Высокоинтенсивные магнитные сепараторы с постоянными магнитами. Известия вузов. Горный журнал, 2001, 4-5, 133 136. [Pelevin A.Ye., Tsipin Ye., Koltynov A.V., Komlev S.G. High intensity magnetik separators with permanent magnets. Izvestiya vuzov. Gornyy Journal, 2001, 4-5, 133-136. (in Russian)].

[10] Килин В.И., Якубайлик Э.К., Верхотуров М.В., Килин С.В. Исследование магнитных характеристик системы неодим-железо-бор в сухих сепараторах. Физико-технические проблемы разработки полезных ископаемых, 2009, 1, 106-111.[Kilin V.I., Yakubailik E.K., Verchotyrov M.V., Kilin S.V. Investigation into magnetic characteristics of neodymium-iron-barium system in dry magnetic separators. Journal of Mining Science, 2009, vol. 45, no. 1, pp. 87-92 (in Russuan, in English)].

[11] Килин В.И. Повымение эффективности магнитной сепаращии магнетитовых руд. Чита: ЧитГУ, 2011. 327 c. [Kilin V.I. Increase effectively magnetic separation magnetite ores. Chita, RIK ChitGU, 2011, 327p. (in Russian)].

[12] Ганженко И.М., Якубайлик Э.К. Снижение потерь магнетита на Абагурской обогатительной фабрике. Обогащение руд, 2015, 1, 22-25. [Ganzhenko I.M., Yakubailik E.K. Magnetite losses decrease at the Abagyrskaya concentrating plant, Obogashchenie rud., 2015, 1, 22-25. (in Russian)]. 